\section{Biological Nutrient Removal in an Intermittently Aerated Bioreactor}

\author{
J. Derco, ${ }^{*}$ B. Urminská, A. Kovács, and K. Šimkovič \\ Department of Environmental Engineering, \\ Faculty of Chemical and Food Technology, \\ Slovak University of Technology, Radlinského 9, \\ 81237 Bratislava, Slovakia
}

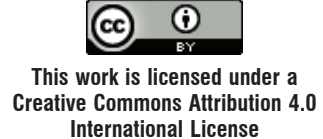

doi: 10.15255/CABEQ.2016.1026

Original scientific paper

Received: October 21, 2016

Accepted: May 30, 2017

The extension of biological processes from carbonaceous impurities removal to nitrogen and phosphorus removal had an impact on the biological system configuration. The system must be well designed, optimized, and operated at its optimum in order to meet the ever more stringent effluent standards. An intermittently aerated completely mixed lab-scale activated sludge bioreactor (IACMB) has been used for modelling biological processes of nutrients removal. Concerning the nitrogen removal, the operating cycles 15-30 (15 minutes of aeration, 30 minutes of only mixing without aeration) and 30-30 were tested. For the experiments with luxury uptake processes, the operating cycles $15-45,15-90,30-60$ and $15-75$ were used. The cycle 15-75 was the most satisfactory with convenient lengths of aerobic, anoxic, and anaerobic period, high efficiency of the nitrification and denitrification processes, and significant decrease in phosphorus concentration. The results have shown that the intermittently aerated bioreactors are suitable for nitrogen removal as well as luxury uptake of phosphorus. The main advantage is high flexibility in maintenance and control of biochemical environments in the bioreactor.

Key words:

denitrification, intermittently aerated completely mixed activated sludge bioreactor, luxury uptake, phosphorus, nutrient removal

\section{Introduction}

Due to the combined emission-immission based approach to effluent wastewater discharge ${ }^{1}$, highly efficient nutrients removal is often necessary also in small wastewater treatment plants, since they are often situated near small receiving streams or in environmentally sensitive areas. The extension of biological processes from carbonaceous impurities removal to nitrogen and phosphorus removal had an impact on the biological system configuration. Not only the system configuration and its operation increased in complexity, but the ever more stringent standards for effluent quality have to be satisfied. To maintain anaerobic, anoxic, and oxic conditions, these processes usually require the use of three separate bioreactors ${ }^{2}$

Intermittently aerated bioreactors are time-based process cycles $^{3}$ which allow maintaining aerobic, anoxic, and anaerobic environment in one reactor depending on time. Thus, in comparison with conventional biological nutrient removal systems, lower investment costs are characteristic for this one-stage bioreactor. This type of bioreactor is a convenient

"Corresponding author: e-mail: jan.derco@stuba.sk, tel.: +421904 171 solution for smaller WWTPs where there is not enough space for spatial segregation of different biochemical environments. In such bioreactors, the aeration of activated sludge tank is controlled according to an appropriate signal (measured variables such as respiration rates, ammonia or nitrate concentrations, oxidation and reduction potential (ORP) or $\mathrm{pH}$, or pre-set time intervals can be applied). Aerators can be switched on and off, which leads to alternating aerobic conditions suitable for carbonization and nitrification, anoxic conditions for denitrification, and anaerobic conditions for luxury uptake process. Activated sludge tank must be continuously stirred to prevent the settling of the sludge.

Because of alternating aerobic, anoxic, and anaerobic conditions in the reactor, the effluent concentrations also fluctuate between minimum and maximum levels under cyclic pseudo-steady state conditions determined by the operating parameters. In the full-scale application, the secondary settling tank serves also as a balancing tank, rendering the fluctuating characteristics of ammonia and nitrate concentrations ${ }^{4}$.

In addition to the sludge age, there are two other specific parameters important for this system. 
The aerated fraction (AF), compatible with the denitrification to total volumes $\left(V_{\mathrm{D}} / V\right)$ ratio of conventional pre-denitrification systems is a fraction of time within a cycle in which the reactor is aerated. According to Hanhan et al., ${ }^{4}$ the recommended use of this parameter has been so far quite empirical, but several studies have reported AF of around 0.50 to be convenient for nitrogen removal. The other parameter is the cycle time ratio (CTR) identifying the ratio of total cycle time to the hydraulic retention time ${ }^{4}$.

Intermittent operation mode is typical for non-continuous biological wastewater systems. Renewed interest in these systems is connected with their lower costs in comparison with continuous flow activated sludge reactors. Such systems may fall into one of the two following major categories ${ }^{5}$ : the continuously fed intermittently decanted system (CFID) or the sequencing batch reactor (SBR). The treatment processes and activated sludge separation performance in one vessel are common for both systems, thus eliminating the need for separate sedimentation tank and activated sludge recycle ${ }^{5}$.

Intermittent aeration can be applied also in continuous flow activated sludge reactor. Sedimentation is carried out in a separate sedimentation tank. Intermittent aeration in such reactor is used for intensification of small WWTPs with regard to nitrogen removal, e.g. for an oxidation ditch ${ }^{6-8}$.

The sludge solids reduction rate and the transformation of nitrogen and phosphorus compounds during the batch aerobic digestion of waste activated sludge carried out with an intermittent aeration were equivalent to those with the continuous aeration, so the power cost for aeration can be saved by using the intermittent aeration method ${ }^{9}$.

Mansouri et al. reported removal efficiencies of COD, TN, and TP in an intermittently aerated $\mathrm{SBR}^{10}$. Murat-Hocaoglu et al. investigated the effect of intermittent aeration on the nitrogen removal performance of a membrane bioreactor treating black water ${ }^{11}$.

Intermittently operated continuously fed systems were reported to be suitable also for the treatment of high-strength industrial wastewater ${ }^{12}$.

An intermittently aerated completely mixed activated sludge bioreactor (IACMB) was used for lab-scale dynamic modelling of simultaneous nitrification and denitrification processes in highly recycled systems industrial Carrousel reactor ${ }^{13-15}$.

The aim of this study was to examine the influence of operating conditions in an intermittently aerated bioreactor (cycle length, length of mixing and aeration) on biological nitrogen removal. The second goal of the work was to examine the influence of operating conditions in IACMB on nitrogen and phosphorus removal (luxury uptake).

\section{Materials and methods}

All experiments have been performed in an intermittently aerated completely mixed lab-scale activated sludge reactor (IACMB). The layout of the lab-scale reactor is shown in Fig. 1. Total volume of the reactor was $4.2 \mathrm{~L}$. The secondary settling tank had volume of $0.9 \mathrm{~L}$. The bioreactor was operated as low-loaded activated sludge process with model wastewater flow $2.1 \mathrm{~L} \mathrm{~d}^{-1}$, i.e. hydraulic retention time (HRT) of the wastewater in the bioreactor was approximately 48 hours.

Intermittent supply of dissolved oxygen to the system was controlled by timer. The initial biomass concentration in the bioreactor was about $3 \mathrm{~g} \mathrm{~L}^{-1}$. The concentration of nutrients ( $\mathrm{N}$ and $\mathrm{P})$ as well as synthetic organic contamination in the wastewater was higher than the concentration of these substances in the municipal wastewater regarding the aims of the study, i.e. the possibilities of using this system for the removal of $\mathrm{N}$ and $\mathrm{P}$ from the wastewater. Sludge age in the reactors was maintained at approximately 15 days.

The cycle time of $45 \mathrm{~min}$, and the aeration time of 15 min were used during performing the aforementioned pulse changes of the synthetic wastewater input composition. The activated sludge from a municipal wastewater treatment plant was acclimated to the synthetic wastewater by cultivation in the reactor for two months. The reactor was operated at mean organic loading $0.19 \mathrm{~g}$ of $\mathrm{BOD}_{5} \mathrm{~g}^{-1}$ MLVSS $\mathrm{d}^{-1}$ ( $\mathrm{g}$ of $\mathrm{BOD}_{5}$ per $\mathrm{g}$ of mixed liquor volatile suspended solids per day) and solid retention time (SRT) was $15 \mathrm{~d}$ in order to maintain nitrifying activated sludge.

As already mentioned, the second goal of the study was experimental modelling of nitrogen and phosphorus removal from synthetic wastewater by the IACMB. The composition of model wastewater is given in Table 1. Sodium acetate, glucose, ethanol, and peptone were used as organic components of the model wastewater.

The cycle time varied from $60 \mathrm{~min}$ to $120 \mathrm{~min}$, and the aeration period was altered from 15 to 30 min, in order to determine the most convenient oxygen environment for nutrient $(\mathrm{N}$ and $\mathrm{P})$ removal in the reactor. The reactor was operated at mean organic loading $0.09 \mathrm{~g} \mathrm{BOD}_{5} \mathrm{~g}^{-1}$ MLVSS d$^{-1}$ and SRT was $15 \mathrm{~d}$. Mean value of HRT was $20 \mathrm{~h}$.

The reactor was aerated by air diffusers. The time of aeration was controlled by timer. Laboratory measurements were carried out at a temperature of approximately $20^{\circ} \mathrm{C}$.

The analyses of COD, mixed liquor suspended solids (MLSS), and mixed liquor volatile suspended solids (MLVSS), ammonium, nitrite, nitrate phos- 

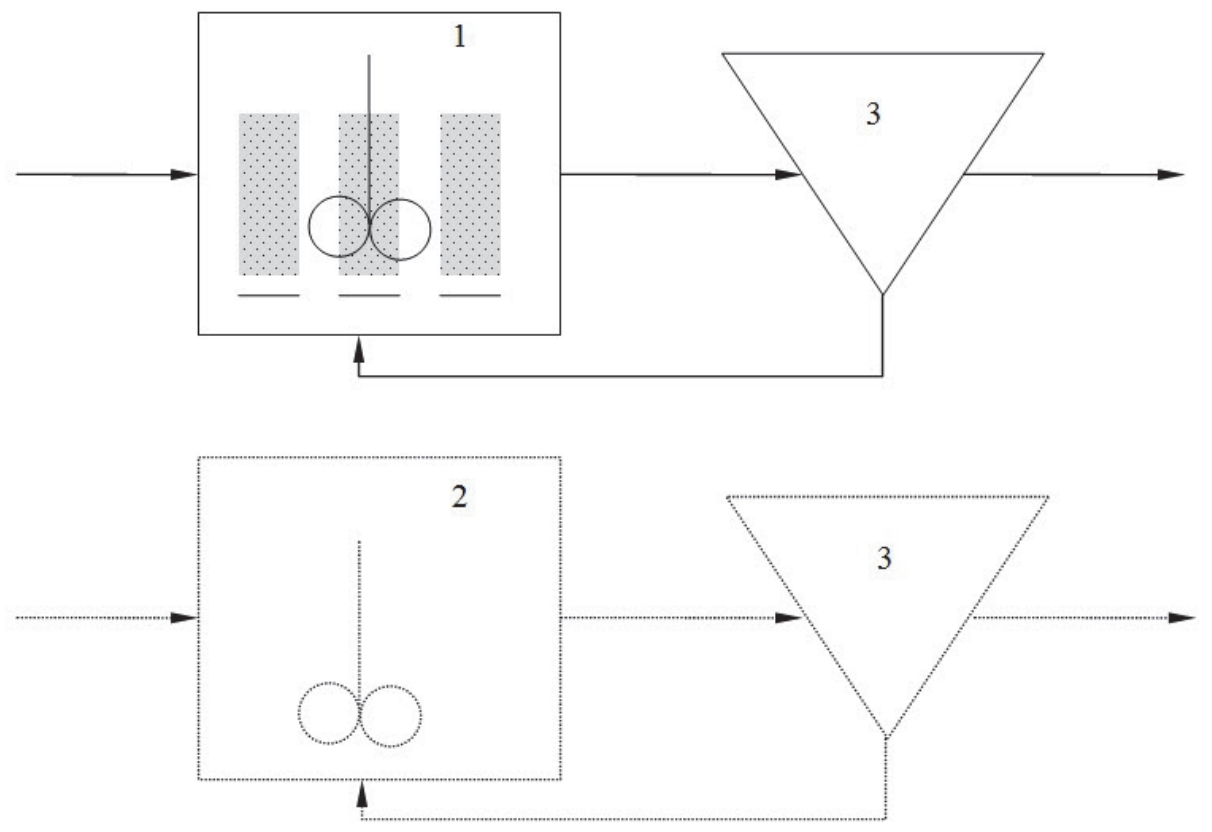

Fig. 1 - Scheme of an intermittently aerated completely mixed bioreactor IACMB; 1 - aerobic conditions, 2 - anoxic conditions, 3 - sedimentation tank

phorus, and cadmium concentrations were performed in accordance with standard methods ${ }^{16}$. The dissolved oxygen concentrations were measured by Syland Dissolved Oxygen Meter.

The model wastewater contained easily degradable organic substances (sodium acetate, glucose, ethanol, and peptone) as a source of organic pollution. In the first phase of the experiments, the amount of organic compounds in the substrate was equivalent to $\mathrm{COD}=400-600 \mathrm{mg} \mathrm{L}^{-1}$. In the second phase, the value of COD was $1500 \mathrm{mg} \mathrm{L}^{-1}$.

Organic nitrogen contained in the peptone and the added $\mathrm{NH}_{4} \mathrm{Cl}$ were sources of ammonia nitrogen. Its concentration in the first phase was equal to $45-50 \mathrm{mg} \mathrm{L}^{-1}$ and in the second phase $35-40 \mathrm{mg} \mathrm{L}^{-1}$ In addition, this value had to be increased 1.5 times to approximately $53 \mathrm{mg} \mathrm{L}^{-1}$.

Phosphorus (phosphate form) was intentionally added to the wastewater in excess because of the possibility of its enhanced removal - luxury uptake. The concentration of phosphorus in the wastewater in the first phase ranged from 15 to $20 \mathrm{mg} \mathrm{L}^{-1}$. In

Table 1 - Composition of model wastewater ( $N$ and P removal)

\begin{tabular}{ccc}
\hline & Content & Unit \\
\hline $\mathrm{COD}$ & 900 & $\mathrm{mg} \mathrm{L}^{-1}$ \\
$\mathrm{BOD}_{5}$ & 540 & $\mathrm{mg} \mathrm{L}^{-1}$ \\
$\mathrm{~N}^{-N_{4}}{ }^{+}$ & 90 & $\mathrm{mg} \mathrm{L}^{-1}$ \\
$\mathrm{P}^{-\mathrm{PO}_{4}^{3-}}$ & 20 & $\mathrm{mg} \mathrm{L}^{-1}$ \\
\hline
\end{tabular}

the second phase, it was $10 \mathrm{mg} \mathrm{L}^{-1}$ and this value was also increased at the end of the second phase to $15 \mathrm{mg} \mathrm{L}^{-1}$.

In the first phase of the experiments, the focus was on the influence of operating conditions in the bioreactor on nitrogen removal. The changes in concentrations of dissolved oxygen, $\mathrm{NH}_{4}-\mathrm{N}, \mathrm{NO}_{2}-\mathrm{N}$, $\mathrm{N}-\mathrm{NO}_{3}, \mathrm{PO}_{4}-\mathrm{P}$ were measured.

In the second phase of the experiments, the main concern was to examine the influence of the operating conditions in the bioreactor on the removal of nitrogen and phosphorus. In the lab-scale bioreactor, we applied various aerobic and anoxic periods. During each operating cycle, the changes in concentrations of dissolved oxygen, $\mathrm{NH}_{4}-\mathrm{N}, \mathrm{NO}_{2}-\mathrm{N}$, $\mathrm{N}-\mathrm{NO}_{3}, \mathrm{PO}_{4}-\mathrm{P}$ with time were measured.

\section{Results and discussion}

The main objective of the work was to investigate the potential of biological nutrient removal in an intermittently aerated completely mixed activated sludge bioreactor in lab-scale.

\section{Nitrogen removal}

Fig. 2 shows oxygen, ammonium, nitrite, nitrate, and phosphorus concentration profiles in the IACMB, while the whole cycle time was $45 \mathrm{~min}$, the aeration time was $15 \mathrm{~min}$, and the time of mixing without oxygen supply was $30 \mathrm{~min}$ (i.e. the operating cycle 15-30). 


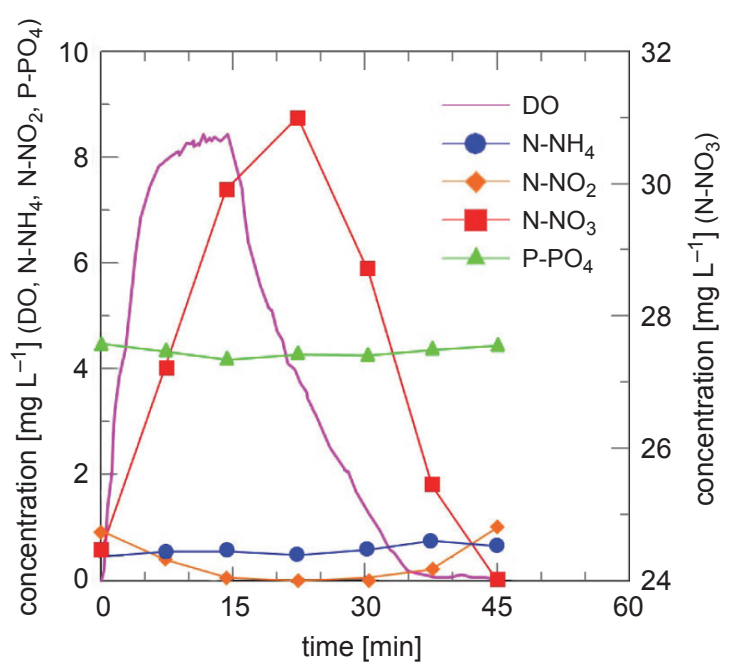

Fig. 2 - Oxygen, ammonium, nitrite, nitrate, and phosphorus concentration profiles in the IACMB. Operating cycle (15-30), $t_{\text {aer }}=15 \mathrm{~min}, t_{\text {mix }}=30 \mathrm{~min}$.

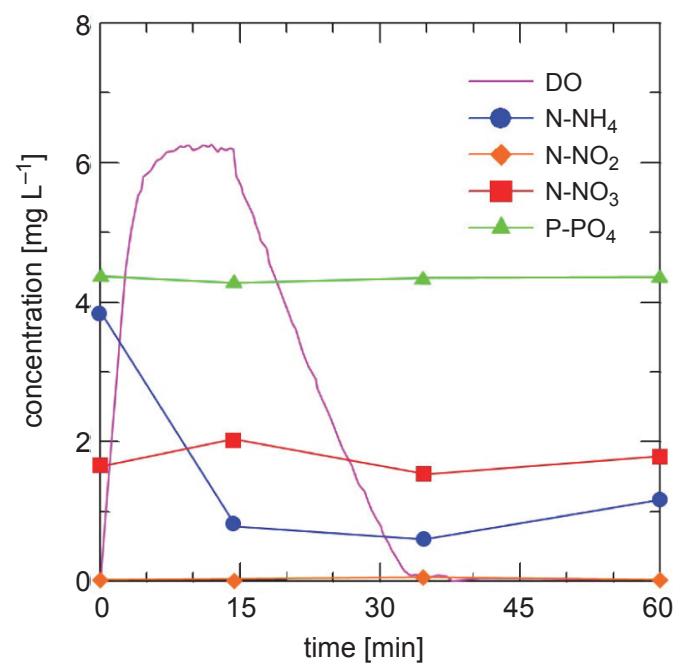

Fig. 3 - Oxygen, ammonium, nitrite, nitrate, and phosphorus concentration profiles in the IACMB. Operating cycle 30-30, $t_{\text {aer }}=30 \mathrm{~min}, t_{\text {mix }}=30 \mathrm{~min}$.

Observed concentration values of ammonium nitrogen and nitrite nitrogen within operating cycle were relatively low (about $1.0 \mathrm{mg} \mathrm{L}^{-1}$ ). The concentration of nitrite nitrogen dropped almost to zero during the aerobic phase; afterwards it increased to the original value. This can be explained by oxidation of nitrite nitrogen into nitrate in the aerobic environment and partial reduction of nitrate nitrogen back to the nitrites during the anoxic phase of the cycle.

On the other hand, concentration values of nitrate nitrogen were quite high (about $30 \mathrm{mg} \mathrm{L}^{-1}$ ) as a result of the nitrification process in the system. During the oxic phase, the concentration of nitrate nitrogen increased significantly compared to the other forms of investigated inorganic compounds of nitrogen. The maximal concentration of the nitrate nitrogen in the system was more or less equivalent to the available amount of ammonia nitrogen in the substrate. However, the denitrification process remained incomplete due to the short anoxic period, which led to an accumulation of the nitrates in the system.

It can be concluded that this operating cycle was appropriate for the nitrification process. However, conditions for the effective process of denitrification had not been created as only 15 minutes were left for the anoxic conditions within the cycle. In addition, a serious problem occurred as the settling properties of the activated sludge were gradually deteriorating because of the excessive growth of filamentous microorganisms.

Oxygen, ammonium, nitrite, nitrate, and phosphorus concentration profiles in the IACMB after changing the operating parameters are shown in Fig. 3. In this case, the cycle length was $60 \mathrm{~min}$, while the aeration time was changed to $30 \mathrm{~min}$, i.e. operating cycle 30-30 was maintained.

From Fig. 3 it is obvious that the most significant change was in the concentrations of nitrite nitrogen. These concentrations were almost zero during the whole cycle. For comparison, during the previous measurements at the same operating cycle, the $\mathrm{N}^{-\mathrm{NO}_{2}}$ concentrations were up to $10 \mathrm{mg} \mathrm{L}^{-1}$.

In the aerobic environment, the concentration of ammonia nitrogen was decreasing equally to the increase in the concentration of nitrates. On the contrary, in the anoxic period, the concentration of nitrate nitrogen was decreasing with the increase in ammonia nitrogen. However, the differences in these concentrations were quite small. It should be mentioned that effluent concentrations of total inorganic nitrogen did not exceed $1.0 \mathrm{mg} \mathrm{L}^{-1}$. Concerning the fact that influent concentration of ammonia nitrogen was approximately $40 \mathrm{mg} \mathrm{L}^{-1}$ and the model wastewater contained approximately $41 \mathrm{mg} \mathrm{L}^{-1}$ of organic nitrogen, the efficiency of the nitrogen removal under the conditions of the operating cycle 30-30 was very high, and the conditions in the reactor were convenient for the simultaneous nitrification and denitrification processes.

On the other hand, it should be mentioned that the amount of mixed liquor suspended solids (MLSS) was permanently low due to the ongoing troubles with excessive growth of filamentous microorganisms, bad settling properties of the activated sludge, and its washing away from the reactor.

Regarding the phosphorus removal, similarly to the previous operating cycle, the phosphorus concentration in the system was around $4.0 \mathrm{mg} \mathrm{L}^{-1}$. 


\section{Nitrogen and phosphorus removal}

Experimental modeling of biological nutrient $(\mathrm{N}$ and $\mathrm{P}$ ) removal has been also carried out in the intermittently aerated lab-scale completely mixed activated sludge bioreactor. The aim was to find appropriate operating conditions with regard to the cycle time and times for individual reaction phases. It is well known that performance of the aforementioned processes requires the sequence of anaerobic (hydrolysis of complex substrate in order to create readily biodegradable components and consequently reserve material in specific bacteria cells), aerobic (nitrification and enhanced biological removal of phosphorus by the specific bacteria cells), and anoxic (denitrification) periods. It should be mentioned that strong competition between activated sludge heterotrophic microorganisms with regard to organic substrate occurs in such biological systems. The highest energy gain corresponds to aerobic transformation of organic wastewater components. On the other hand, the lowest gain of energy is typical for anaerobic biochemical transformation of organic wastewater components. This means that nitrates and dissolved oxygen have an inhibition effect on anaerobic processes, and consequently on enhanced biological removal of phosphorus in a one sludge bioreactor.

For the experiments, the operating cycles 15 45, 15-90, 30-60, and 15-75 were used. In the first cycle (15-45), the total length of the cycle was 60 minutes with length of aeration of $15 \mathrm{~min}$. It was estimated that the time for anoxic and anaerobic conditions would be about 30 minutes in each cycle - after 15 minutes of aeration and another 15 minutes for the decrease the amount of dissolved oxygen by sludge respiration activity. However, this time proved insufficient, and high concentrations of nitrate nitrogen were measured at the effluent. Conversely, the effluent ammonium concentrations were low and nitrite nitrogen concentrations did not exceed $0.5 \mathrm{mg} \mathrm{L}^{-1}$. During aeration, a significant decrease in phosphorus in the system was not observed. The concentrations of dissolved phosphorus in the reactor were about $10 \mathrm{mg} \mathrm{L}^{-1}$. This operating cycle was convenient only for the nitrification, but not for the denitrification or the luxury uptake of phosphorus.

The same applies to the cycle 15-90, but also the amount of filamentous microorganisms was too high and the biomass concentration was continuously decreasing.

The concentration profiles of oxygen, ammonium, nitrite, nitrate, and phosphorus in the IACMB when the operating cycle 30-60 was applied are shown in Fig. 4. The cycle time in this case was 90 min (the aeration time $30 \mathrm{~min}$ and the time of mixing, i.e. without oxygen supply $60 \mathrm{~min}$ ).
The decrease in ammonium and nitrite concentration values close to zero, and the increase in nitrate content during aeration period are obvious from Fig. 4. Only a slight decrease in phosphorus content in the bioreactor occurred. On the other hand, after the mixing-only period (anoxic conditions), the concentration values of nitrates reached more or less the initial value, i.e. the value typical for the beginning of aeration period. Insufficient denitrification efficiency and consequently negligible efficiency of biologically enhanced removal of phosphorus were typical for these operating conditions.

Fig. 5 shows oxygen, ammonium, nitrite, nitrate, and phosphorus concentration profiles in the

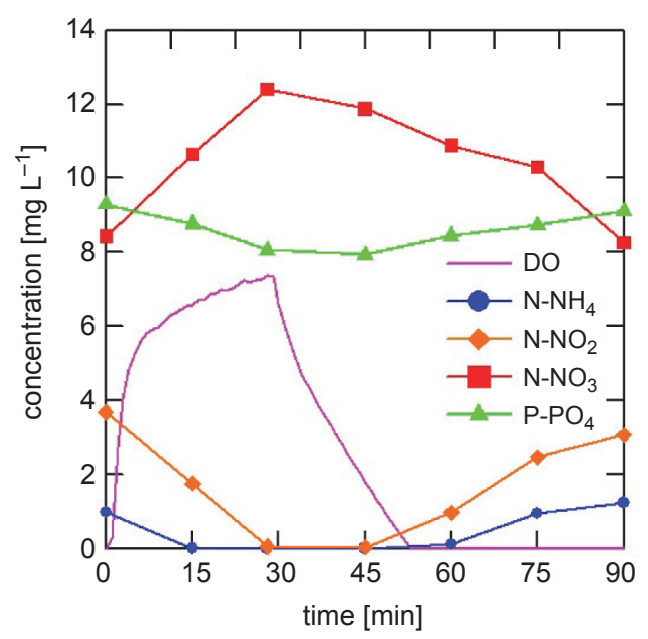

Fig. 4 -Oxygen, ammonium, nitrite, nitrate, and phosphorus concentration profiles in the IACMB. Operating cycle 30-60, $t_{\text {aer }}=30 \mathrm{~min}, t_{\text {mix }}=60 \mathrm{~min}$.

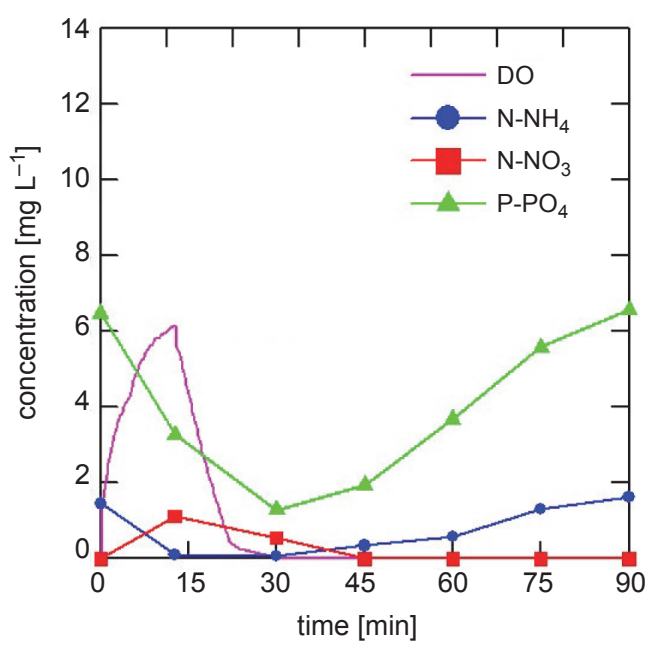

Fig. 5 - Oxygen, ammonium, nitrite, nitrate, and phosphorus concentration profiles in the IACMB. Operating cycle 15-75, $t_{\text {aer }}=15 \mathrm{~min}, t_{\text {mix }}=75 \mathrm{~min}$. 
IACMB after changing of the operating parameters. The whole cycle time in the bioreactor was the same, i.e. $90 \mathrm{~min}$, and the aeration time was reduced to 15 min (mixing period, i.e. without oxygen supply $75 \mathrm{~min}$ ). Significant decrease in phosphorus content in the reactor during aeration period can be seen in Fig. 5.

Ammonium concentration did not exceed $2 \mathrm{mg} \mathrm{L}^{-1}$ and nitrite concentration was below $1.0 \mathrm{mg} \mathrm{L}^{-1}$. Increased efficiency of biologically enhanced removal of phosphorus and very low effluent concentration values of ammonium, nitrite, and nitrate concentration values were obtained after changing the operating conditions. However, it should be mentioned that activated sludge bulking occurred during these experiments.

\section{Conclusions}

Concerning the nitrogen removal, the operating cycle 15-30 min (15 minutes of aeration and 30 minutes of mixing, i.e. without oxygen supply) was not satisfactory, as the aerobic conditions prevailed substantially over anoxic, and the concentration of nitrate nitrogen at the effluent was high.

The cycle 30-30 was better; concentrations of inorganic nitrogen at the effluent were very low. On the other hand, the sedimentation properties of the sludge were bad and excessive growth of filamentous microorganisms was observed.

For the experiments with luxury uptake processes, used were operating cycles 15-45, 15-90, 30-60, and 15-75. The cycle 15-45 was unsatisfactory because effluent concentrations of nitrate nitrogen were high, and luxury uptake of phosphorus did not occur. The cycle 15-90 was also unsatisfactory. The cycle 30-60 was also unsuitable - relatively short anoxic/anaerobic period was sufficient for denitrification, but not for the luxury uptake process. The sludge filamentation occurred in the cycle 1575 as well, but it was partly suppressed at the operation of the system without external recirculation of activated sludge. This cycle was the most satisfactory with convenient lengths of aerobic, anoxic, and anaerobic period, high efficiency of the nitrification and denitrification processes, and significant decrease in phosphorus concentration.

Overall, the results have shown that intermittently aerated bioreactors are suitable for nitrogen removal as well as luxury uptake of phosphorus. The main advantage is the flexibility of possible changes of conditions in the bioreactor. However, the hydrodynamic regime of the reactor, alternating oxic, anoxic, and anaerobic conditions, and the occurrence of low concentrations of dissolved oxygen, organic substrate, and nutrients can lead to exces- sive growth of the filamentous microorganisms in the bioreactor. This fact increases the requirements for control and process management.

\section{ACKNOWLEDGEMENTS}

This work was supported by the Slovak Research and Development Agency under the contract No. APVV-0656-12. The authors also wish to thank for the support from VEGA Grant 1/0859/14.

\section{References}

1. European Commission, Directive 2000/60/EC of the European Parliament and of the Council of 23 October 2000 establishing a framework for community action in the field of water policy, Off. J. Eur. Communities, L 327/1 (2000).

2. Yilmaz, G., Lemaire, R., Keller, J., Yuan, Z., Effectiveness of an alternating aerobic, anoxic/anaerobic strategy for maintaining biomass activity of BNR sludge during longterm starvation, Water Res. 41 (2007) 2590. doi: https://doi.org/10.1016/j.watres.2007.02.011

3. Rezaee, S., Zinatizadeh, A. A. L., Asadi, A., Comparative study on effect of mechanical mixing and ultrasound on the performance of a single up-flow anaerobic/aerobic/anoxic bioreactor removing CNP from milk processing wastewater, Ultrason. Sonochem. 23 (2015) 289.

doi: https://doi.org/10.1016/j.ultsonch.2014.10.018

4. Hanhan, O., Güçlü, I., Yagci, N. O., Artan, N., Orhon, D., Mechanism and design of intermittent aeration activated sludge process for nitrogen removal, Journal of Environmental Science and Health Part A 46 (2011) 9.

doi: https://doi.org/10.1080/ 10934529.2011.526073

5. Argaman, Y., Nitrogen removal in a semi-continuous process, Wat. Res. 20 (1986) 173.

doi: https://doi.org/10.1016/0043-1354(86)90007-2

6. Araki, H., Koga, K., Inomae, K., Kusuta, T., Away, Y., Intermittent aeration for nitrogen removal in small oxidation ditches, Wat. Sci. Tech. 34 (1990) 131.

7. Heduit, A., Duchene, P, Sintes, L., Optimization of nitrogen removal in small activated sludge plants, Wat. Sci. Tech. 22 (1990) 123.

8. Nakajima, J., Kaneko, M., Practical performance of nitrogen removal in small-scale sewerage treatment plants operated in intermittent aeration mode, Wat. Sci. Tech. 23 (1991) 709.

9. Kim, S. H., Kim, W. J., Chung, T. H., Release characteristics of nitrogen and phosphorus in aerobic and intermittent aerobic sludge digestion, Korean J. Chem. Eng. 19 (2002) 439. doi: https://doi.org/10.1007/BF02697154

10. Mansouri, A. M., Zinatizadeh, A. A., Irandoust, M., Akhbari, $A$., Statistical analysis and optimization of simultaneous biological nutrients removal process in an intermittently aerated SBR, Korean J. Chem. Eng. 31 (2014) 88. doi: https://doi.org/10.1007/s11814-013-0183-8

11. Murat-Hocaoglu, S., Atasoy, E., Baban, A., Insel, G., Orhon, D., Nitrogen performance of intermitently aerated membrane bioreactor treating black water, Environmental Technology 34 (2013) 2717.

doi: https://doi.org/10.1080/09593330.2013.786139

12. Bell, B. A., Hardcastle, G. J., Treatment of a high-strength industrial waste in a continuously fed intermittently operated, activated sludge system, Journal of the Water Pollution Control Federation 56 (1984) 1160. 
13. Derco, J., Králik, M., Hutñan, M., Bodik, I., Černák, R. Modelling of the carrousel plant, Wat. Sci. Tech. 30 (1994) 345.

14. Derco, J., Kovács, A., Králik, M., Shansab, S., Modelling of an intermittently aerated completely mixing activated sludge reactor, Mathematical and Computer Modelling of Dynamical Systems 5 (1999) 313.

doi: https://doi.org/10.1076/mcmd.5.4.313.3673
15. Derco, J., Králik, M., Kovács, A., Modelling of nutrient removal processes in an intermittently aerated bioreactor, J. Chem. Biochem. Eng. Q. 15 (2001) 167.

16. Greenberg, A. E., Clesceri, L. S., Eaton, A., Standard methods for the examination of water and wastewater, American Public Health Association, Washington DC, 2005, 22 ${ }^{\text {nd }}$ edition. 